\title{
VEKÂLETSİZ İŞ GÖRMENİN TEMSIL HUKUKUNDA UYGULAMA ALANI BULDUĞU HALLER
}

Dr. Ismail KIRCA*

\section{VEKÂLETSIZ IŞ GÖRME VE TEMSLL. KAVRAMLARININ KARŞILAŞTIRILMASI}

14.6.1881 tarihli Isviçre Borçlar Kanunu'na ilişkin olarak hazırlanmış olan Üçüncui Tasarı'nın ${ }^{1}$ vekâletsiz iş görmeyi düzenleyen son hüküm niteliğindeki 480 . maddesinde şöyle bir hüküm öngörülmüștü: "Vekâlet ve temsile ilişkin hükümler, [vekâlesiz iş görmeyle ilgili] bu Bab'in hükümlerine ve [vekâletsiz] iş görmenin niteliğine aykırı düşmediği sürece kuyasen burada da uygulanır." Kanunlaşmayan bu hükümden, 1881 tarihli İsviçre Borçlar Kanunu'nun daha hazırlık çalışmaları esnasında, vekâlet, vekâletsiz iş görme ve temsil kurumlarının birbirleriyle bağlantılt görüldüğü anlaşılmaktadır. Her üç kurum da, şu ya da bu şekilde başkası hesabına (für einen andern) hareket olgusuyla yakından ilgilidír.

Vekâletsiz iş görme ile temsil arasında bu noktada bir benzerlik bulunmakla birlikte, her iki kurum, uygulama alanları bakımından esas itibariyle birbirinden farklıdır. Vekâletsiz iş görme, iş gören ile iş sahibi arasındaki if ilişkiyi ilgilendiren bir husustur ${ }^{2}$. Is ş gören, iş sahibi adına hareket etmiş olsa bile, câiz olan vekâletsiz iş

(*) A.Ü. Hukuk Fakültesi Ticaret Hukuku Anabilim Dalı Araştırma Görevlisi

1. Dritter Entwurf zum Bundesgesetz iber das Obligationenrecht, bearbeitet nach den Beschlüssen einer Kommission vom 16-21.5.1876 und vom 18.9-7.10.1876, Bem 1877.

2. Schmid, Jörg: Die Geschäftsführung ohne Auftrag, Freiburg (Schweiz) 1992, Rdnr. 406 vd.; Lischer, Urs: Die Geschäftsführung ohne Auftrag im schwezerischen Recht, Diss:, Basel 1990, sh. 121. Vekâletsiz iş görmenin sadece iş sahibi ile iş gören arasındaki ilişkiyle sınırtı tutulması, bazı hallerde bir takım sorunların ortaya çlkmasına sebebiyet verir. Bu haller için bkz. Schmid: Rdnr. 413 vd. 
görmede dahi, onu üçüncü kişiler karşısında borç altına sokamaz ${ }^{3}$. Uçüncü kişilerle olan dıs ilişki, temsil hukukuna ilişkin kurallar (BK $32 \mathrm{vd.)} \mathrm{tarafından} \mathrm{tanzim} \mathrm{edilir}{ }^{4}$. BK 32'vd.'nda önemli olan, temsilcinin sahip olduğu yetkiye istinaden bir başkası adına hareket edip etmediği, ya da (sözde) temsil olunanın, temsilci sıfatıyla haraket eden kişinin yetkisiz olarak üçüncỉ kişiyle yapłığı işleme icazet verip vermediğidir (BK 38-39).

Iç ve dış ilişki ayırımı ve vekâletsiz iş görmenin yalnız iç ilikiyle sınırlı olması bizi şu sonuçlara götürür:

- Kendi ya da bir başkası adına hareket, sadece dış ilişkide önem taşıyan bir husustur. Iş görenin kendi veya iş sahibi adına hareket edip etmemesi, vekâletsiz iş görmede herhangi bir rol oynamaz ${ }^{5}$. Keza BK 410 (İsvBK 419) anlamında başkasının hesabına (für einen andern) iş görme, hiç bir şekilde başkası adına hareketi şart kılmaz ${ }^{6}$. Aynı şekilde iş görenin kendi adına hareketi de, vekâletsiz iş görmeye ilişkin BK $410 \mathrm{vd}$. hükümlerinin uygulanmasını engellemez. Kısacası, başkası adına hareket, vekâletsiz iş görmenin bir unsuru değildir ${ }^{7}$.

- Diğer taraftan, iş görenin yetkisiż olarak ya da iş sahibinin verdiği yetkiye istinaden hareket etmiş olması da, tek başına vekâletsiz iş görme bakımından önem taşımaz ${ }^{8}$. Bu anlamda vekâletsiz iş görmeye ilişkin hükümlerin uygulanabilmesinin tek şartı, iş görmenin vekâlet olmaksızın (ohne Auftrag) gerçekleşmesidir. Diğer bir ifadeyle, vekâletsiz iş görmeden söz edilebilmesi için iş görenin iş sahibine karşı 0 işin yapılması hususunda bir yükümlilğüuüun bu-

3. Bkz. Schmid: Rdnr. 410. Vekâletsiz iş gơrme hukukunda, vekâlet hukukuna ilişkin BK 388/I'ye benzer bir hüküm bulunmamaktadir. BK 388/I'ye göre, "Vekâlet, vekilinin tekabbül eylediği işin yapılması için icap eden hukukî tasarrufları ifa salâhiyetini şâmildir."

4. Lischer: sh. 121; Reichel, Hans: "Geschäftsfithrung ohne Auftrag und Vertretung ohne Vertretungsmacht", SIZ $26(1930)$, sh. 199.

5. Oser/Schönenberger: Kommentar zum Schweizerischen Zivilgesetzbuch, Das Obligationenrecht, Bd. V/3 (Art. 419-529), Zürich 1945, Art. 419 Nr. 8; Lischer: sh.121.

6. Schmid: Rdnr. 1361.

7. Oser/Schönenberger: Art. 419 Nr. 3; Reichel: sh. 199; Schmid: Rdnr. 1361; Lischer: sh. 121.

8. Schmid: Rdnr. 1362 . 
lunmaması gerekir ${ }^{9}$. Dolayısıyla, surf bir yetkinin varlığı, vekâletsiz iş görmeye ilişkin hükümlerin uygulanmasına engel teşkil etme ${ }^{10}$.

\section{VEKÂLETSIZ IŞ GÖRMENIN TEMSIL HUKUKUNDA UYGULAMA ALANI BULDUĞU HALLER}

Temsil yetksinin varlığının ya da yokluğunun, tek başına, vekâletsiz iş görme bakımından önem taşımadığı tesbitini yaptığımıza göre, aşağıda vekâletsiz iş görmenin temsil hukukunda uygulama alanı bulduğ halleri incelemek istiyoruz. Burada, temsilcinin bir yetkiye istinaden temsil olunan adina hareket etmesiyle yetkisiz temsil hallerini ayn ayn ele almak gerekir.

\section{A- Temsil Yetkisinin Varlı̆̆ Halinde}

Temsilcinin temsil edilen adına hareket etmesi şartıyla üçüncü kişiyle yaptığı sözleşmeden doğan haklar ve borçlar, doğrudan doğruya temsil edilene geçer. Temsilci, bu sözleşmeden dolayı ne hak sahibi olur ne de borç altına girer. Kısacası, ùçüncỉ kişiyle olan (dış) ilişkiyi, BK 32 vd.' 'ndaki kurallar belirler.

Buna karşılık, temsilci ile temsil olunanın birbirine karşı yöneltmeleri muhtemel taleplerin (örneğin, temsilcinin yaptı̆ğ masrafların tazmini, ücret talebi; temscilcinin temsil yetkisini kötüye kullanması sebebiyle temsil olunanın uğradığı zararın tazmini talebi vs.) hangi esaslara göre istenebileceği ise, temsilcinin temsil yetkisini kullanma husunda yükümlü, ya da bu konuda sadece yetkili olup olmadı̆̆na göre tayin edilir.

Temsilcinin temsil yetkisini kullanma hususunda yükümlü olduğu hallerde, temsil olunan ile aralarında çıkacak uyuşmazlıklar, temsil yetkisinin kullanılması ' hususunda yükümlülïik getiren (temeldeki) hukukî ilişkiye göre çözüme bağlanır ${ }^{11}$.

Temsilci, temsil yetkisini kullanma hususunda herhangi bir akdî yükümlülü̈̆̆ü bulunmaksızın, bu hususta sadece bir yetkiye sahip ise, temsil olunan ile aralarındaki (iç) ilişkide vekâletsiz iş görmeye

9. Lischer: sh. 121-122; Schmid: Rdnr. 1358-1362.

jo. Oser/Schönenberger: Art. 419 Nr. 8; Lischer: sh. 121; Schmid: Rdnr. 1359-1363. Kars. Lent, Friedrich: Der Begriff der auftraglosen Geschäftsfithrung, Leipzig 1909, sh.162-163; Tandogan, Halukk: Mukayeseli ve Hususiyle Türk- Isviçre Hukuku Bakımundan Vekâletsiz Iş Görme, Istanbul 1957, sh. 133-134.

11. Lischer: sh. 122. Bu hukukî ilişki ise, genelliḳ̣ vekâlet veya hizmet sözleşmesidir. 
ilişkin kurallar uygulama alanı bulur ${ }^{12}$. Bu durumda aynca temsilcinin davranışının câiz olan, ya da câiz olmayan vekâletsiz iş görme niteliğinde olup olmadığına da bakmak gerekir:

Eğer ortada câiz olan bir vekâletsiz iş görme ${ }^{13}$ varsa, temsil olunan (iş sahibi), temsilcinin (iş gören) ömeğin iş görme dolayısıyla yaptığı masrafları tazmin etmekle yükümlüđür (BK 413$)^{14}$.

Bazı haller vardır ki, burada temsilci, temsil yetkisinin sınırları içinde kalmış olmakla beraber, temsil olunan menfaatine aykırı davranarak kendisinin, ya da üçüncü kişinin yararına bu yetkisini kötüye kullanmış olabilir ${ }^{15}$. Eğer temsil yetkisinin temelinde herhangi bir sözleşme bulunmuyor ve üçüncü kişinin iyiniyetli olmas1 ${ }^{16}$ nedeniyle temsil olunan yapılan işlemle bağlıysa, yetkinin kötüye kullanılması halinde temsilcinin sorumluluğu, vekâletsiz iş görmeye ilişkin hükümlere göre (BK $410 \mathrm{vd}$.) tayin edilir. Burada câiz olmayan vekâletsiz iş görme söz konusu olup, temsilcinin yaptığı işlemle bağlı olan temsil olunan, bu yüzden uğramış olduğu zararının tazminini BK $411^{\prime} \mathrm{e}$ istinaden temsilciden isteyebilir ${ }^{17}$.

12. Lischer: sh.122. Karş. Reichel: sh.199.

13. Câiz olan vekâletsiz i̧̧ görmede iş gören, iş sahibinin menfaatine ve gerçek ya da tahmin olunan (varsayılan) amacına uygun hareket etmektedir. Bu konuda aynntılı bilgi için bkz. Tandoğan: sh.176 vd.; Yavuz, Cevdet: Türk Borçlar Hukuku, Özel Hiikümler, C.II, Genişletilmiş ve yenilenmiş B.2, Istanbul 1993, sh, 340 vd.; Lischer: sh. 53 vd.

14. Von Büren, Bruno: Schweizerisches Obligationenrecht, Besonder Teil, Zürich 1972, sh. 335; Lischer: sh. 122.

15. Temsil yetkisinin kötủye kullanılması ve buna bağlanan sonuçlar hususunda bkz. Egger, A.: "Missbrauch der Vertretungsmacht", Beiträge zum Handelsrecht, Festgabe zum 70. Geburtstage von Carl Wieland, Basel 1934, sh. 47 vđ.; Esener, Turhan: Mukayeseli Hukuk ve Hususiyle Türk-Isviçre Borçlar Hukuku Bakımindan Sâlahiyete Mỉstenit Temsil, Ankara 1961, sh.85 vd.; Kutlu-Sungurbey, Ayfer: Yetkisiz Temsil, tstanbul 1988, sh. 12 vd;; BGE 77 II 143 vd.; HGK, 13.2.1974, E.524, K. 103 (YKD 1975, S.9, sh. 9-11).

16. Temsil yetkisinin kötüye kullanıldığın bilmeyen ya da bunu bilmesi kendisinden beklenemeyen kişi, iyiniyetli sayılır. Bkz. dn. 15'de antan eserler ve mahkeme kararlan.

17. Gautschi, Georg: Berner Kommentar, Bd. VI, 2 Abteilung, 5. Teilband, 2., neubearbeitete Aufl. des von Dr. H.Becker begründeten Kommentars, Bem 1964, Vorbem. zum Geschäfsführung ohne Auftrag, Nr. II(2) ve Art. 423 Nr. 2b(2); Lischer: sh. 123; Reichel: sh. 199; von Büren, Brono: Schweizerisches Obligationenrecht, Allgemeiner Teil, Zürich 1964, sh. 164. Aynı yönde bkz. Schmid: Rdnr. 1363.

Buna karşılık îçü̈ncỉ kiși kötüiniyetli ise, yani temsilcinin temsil yetkisini kötülye kullandığ biliyor ya da buni bilmesi kendisinden beklenebiliyorsa, temsil olunan yapılan işlemle bağlı olmayacağından herhangi bir zarara uğramaz. Dolayısıyla temsil olunan, surf temsil yetkisinin kötüye kullanılmış olmasi sebebiyle temsilciye karşı tazminat talesinde bulunamaz (Gautschi: Vorbem. zur Geschäftsführung ohne Auftrag, Nr. 11(2); Lischer: sh. 123). 


\section{B. Yetkisiz Temsil Halinde}

Yetkisi bulunmaksızın ${ }^{18}$ başkası adına hareket eden kişi, yetkisiz temsilci konumunda olup, temsil edilenin yapilan işleme icazet vermemesi durumunda üçüncü kişi karşısında BK 39 çerçevesinde sorumlu olur. Temsil edilen ise, (sözde) temscilcinin yetkisiz olarak yaptığı işlemle bağh olmaz (BK 38).

Yetkisiz temsilci ile temsil olunan arasındaki if iliskide, -varsa- tarafların birbirlerine karşı yöneltecekleri talepler, bunlar arasında bir akdî ilişkinin bulunması halinde ilkin bu ilişkiye göre belirlenir. Eğer taraflar arasında akdî bir ilişki bulunmuyorsa, söz konusu talepler, ya vekâletsiz iş görmeye ${ }^{19}$ veya haksız fiile ilişkin hükïmlere ya da culpa in contrahendo'ya ilişkin esaslara göre tayin edilir ${ }^{20}$. Aşağıda, bunlar arasında sadece vekâletsiz iş görmenin uygulama alanı bulduğu halleri inceleme konusu yapacağız.

Burada herşeyden önce şu hususu belirtmekte fayda görüyoruz: Vekâletsiz iş görmenin iç iliş̧kiyi, temsilin ise üçüncü kişiyle olan dış ilişkiyi ilgilendiren bir durum olmasından hareketle, temsil olunan (iş sahibi) iç ilişskide vekâletsiz iş görmeye BK $415^{\prime} \mathrm{e}$ göre ica$\mathrm{zet}^{21}$ vermesi ile dış ilişkide BK 38 uyarınca sözleşmeye icazet vermesi hususları biribirinden bağımsızdır. Buna paralel olarak, temsil olunanın bunlardan birine icazet vermesi halinde, diğerine de icazet vermesi gerektiği konusunda bir yükümlülüğ̈i yoktur. Ayn biçimde, temsil olunanın vekâletsiz is görmeye icazet vermesinden, üçüncui kişi, sözleşmeye de icazet verilmesi yönünde bir talep hak-

18. Yetkisizlik, hiç bir yetkinin bulunmamasından ya da mevcut yetkinin aşilmasından kaynakłanabilir ki, hukukî sonuçları bakımundan bunlar arasında herhangi bir fark yoktur.

19. Temsil yetkisi olmadan başkası adına hareket eden kişinin BK 410 anlamında vekâletinin de bulunmadı̆̆ hallerde, yetkisiz temsil, aynı zamanda bir vekâletsiz is görmé teşkil eder. Bkz. Tandǒgan: sh. 138 vd.; Kutlu-Sungurbey: sh. 29 vd.; Guhl Merz/Kummer: Das Schweizerische Obligationenrecht mit Einschluss des Handels-und Wertpapierrechts, 7 Aufl., Zürich 1980, sh. 149 vd.; Künzle, H.Rainer: Der direkte Anwendungsbereich des Stellvertretungsrechts, Diss., Bern 1986, sh. 53 vo.

20. Bucher, Eugen: Schweizerisches Obligationenrecht, Allgemeiner Teil ohne Deliktsrecht, 2., neubeabeitete und erweiterte Aufl., Zulich 1988, sh. 645-646.

21. BK 415'in mehazı olan IsvBK 424'ün kenar başlığında "Genehmigung" (icazet), metninde ise "Billigung" (onama= uygon bulma=tensip) terimi kullanilmustır. Buradaki onama kavramu, aralarnda benzerlik olmasma ragmen, bir yetkisiz temsilcinin yaptı.্. şr. Bu farklılkk konusunda bkz. Hatemi/Serozan/Arpacr: Borçlar Hukuku, Özel Bolüm, Istanbul 1992, sh. 492-493; Yavuz: sh. 349 dn. 41 b ve sh. 350dn. 42a; Gautschi: Art.424 Nr. 1(b). 
kına sahip olamayacağı gibi, temsil olunanın sözleşmeye icazet vermesinden, yetkisiz temsilci, iç ilişkide vekâletsiz iş görmeye de icazet verilmesi gerektiği konusunda bir hakka sahip değildir ${ }^{22}$.

Temsil olunan, ne yetkisiz temsile, ne de vekâletsiz iş görmeye icazet vermiş olabilir. Bu halde temsil olunan, her ne kadar üu̧üncü kişi karşısında yapılan işlemle bağlı olmaz ise de, eğer söz konusu işlem menfaatine uygun olarak yapılmışsa, yani ortada câiz olan bir vekâletsiz iş görme varsa, müvekkilinin menfaatini gözeterek işlem yapan yetkisiz temsilciye karşı sorumlu olur. Buna göre, yetkisiz temsilci, yaptığı masrafları ve BK 39 uyarınca üçüncï kişiye ödemek zonunda kaldığı tazminatı BK $413^{\prime} \mathrm{e}$ istinaden temsil olunandan isteyebilir ${ }^{23}$. Yapılan işlem temsil olunan menfaatine uygun değil, dolayısıyla câiz olmayan vekâletsiz iş görme söz konusu ise, yetkisiz temsilci BK $413^{\prime} \mathrm{e}$ istinad edeme ${ }^{24}$, işlem nedeniyle yaptığ 1 masraflara ve BK 39 uyarınca üçüncü kişiye ödemek zoruna kaldığı tazminata katlanmak zorundadır ${ }^{25}$.

Temsil olunan, yapılan işleme BK 38 uyarınca icazet vermemiş olmakla birlikte, sadece iç ilişki bakımından vekâletsiz iş görmeye icazet vermiş olabilir. Vekâletsiz iş görmeye icazetin verilmesiyle, temsil olunan ile yetkisiz temsilci arasında vekâlet hükümleri geçerli olur (BK 415) ${ }^{26}$. Bu halde yetkisiz temsilci, yaptığı masrafların tazminini ve üstlendiği borçlardan kurtarılmasını

22. Bkz. Violand, Georges: Die Stellvertretung ohne Ermächtigung (OR 38 und 39), Diss., Bem 1988, sh. 97-98; Zäch, Roger: Berner Kommentar, Bd. VV/1/2/2, Bern 1990, Art. 38 Nr. 64-67; von Tuhr, A. (Cev. Cevat Edege) : Borçlar Hukukunun Umumî Kısmu, C.1-2, Ankara 1983, sh. 357; Kutlu-Sungurbey: sh. 33; BGH, NJW 1951, sh. 398. Kars. GuhlMerz/Kummer: sh. 150. Bununla birlikte uygulamada, temsil olunantn (iş sahibi) vekâletsiz iş görmeye ya da yetkisiz temsile verdiği icazetin, bir diǧerini de kapsayıp kapsamadığt yapılan irade açaklamasından anlaşılamamaktadır. Bu sorun, herşeyden önce irade açıklamasının somut olayın özelliklerine göre yapılacak yorumuna göre çözümlenir. Ancak şïphe halinde, vekầletsiz iş görme ya da yetkisiz temsilden birine verilen veya vemmekten kaçınılan icazetin, bunların her ikisini de kapsadığı kabul edilmelidir (Violand: sh.95-96; Zäch: Art. 38 Nr. 68, 80; Schmid: Rdnr. 709; von Staudinger/Dilcher: J.von Staudingers Kommentar zum Bürgerlichen Gesetzbuch mit Einfübrungsgesetz und Nebengesetzen, 1. Buch, Allgemeiner Teil, §\$ 90-240, 12. Auf, Berlin 1980, §177 Nr. 17; Kutlu-Sungurbey: sh.33).

23. Von Bären:Allgemeiner Teil, sh. 164; von Büren: Besonderer Teil, sh. 335; Zäch: Art. $38 \mathrm{Nr}$. 64; Lischer: sh. 125; Schmid: Rdnr. 506; von Tuhr: sh. 357 dn. 20; BGH, NJW 1951, sh. 398. Karş. LG Saarbrücken, NJW 1972, sh. 1117-1118.

24. Lischer: sh. 126.

25. Icazet vermediği için yapılan işlemle bağh olmayan temsil olunan da, herhangi bir zarara uğramayacağından yetkisiz temsilciye karşı bir talepde bulunamaz (Gautschi: Vorbem. zur Geschäftsfithrung ohne Auftrag. Nr. 9).

26. BK'nın 415. maddesinden ne anlaşılması lâzım geidił̧i, esas itibariyle tartışmaladır. Bu hususta bkz. Tandogen: sh. 251 vd.; Lischer: sh. 108 vd.; Schmid: Rdnr. 698 vd. 
(özellikle BK 39 uyannca üçüncü kişiye ödediği tazminatt) temsil olunandan talep edebilii ${ }^{27}$. Kanaatimizce, vekâletsiz iş görmenin câiz olmayan nitelikte olduğu hallerde, temsil olunanın yetkisiz temsile icazet vermeksizin sadece vekâletsiz iş görmeye icazat vermesi, kendisi açısından bir fayda sağlamaz. Temsil olunanın böyle bir yola, olsa olsa is görmenin câiz nitelikte olduğu hallerde, üçüncủ kişiyle akdî bir iliş̧kiye girişmeksizin işlemin (ekonomik) sonuçlarından yararlanmak istemesi halinde başvurabileceği düşünülebi$\mathrm{lir}^{28}$. Ancak (dış ilişkide) yetkisiz temsile icazet verilmemesi nedeniyle söz konusu sözleşmenin kurulmamış sayılması, temsil olunanın (iş sahibi) bu amaca ulaşmasını engeller. Burada şöyle bir çözüm düşüniulebilir: Yetkisiz temsilci, kunulmamış sayılan sözleşmeyi dolaylı temsil ilişkisi çevresinde kendi adına, fakat temsil olunan hesabına yeniden yaparsa, üçünciü kişi karşısında bu sözleşmenin tarafı olur; hesabına sözleşme yapılan temsil olunan da, sözleşmenin tarafı olmaksızın onun ekonomik sonuçlarından yararlanir. Bunun ise, çok dolambaçlı bir yol olduğu kolayca anlaşılır. Dolayısıyla, iş sahibinin iç ilişikide vekâletsiz iş görmeye icazet verdiği hallerde aynı zamanda dı̧̧ ilişkide yetkisiz temsile de icazet vermesi, doğru bir davranış biçimi olacaktır ${ }^{29}$. Ancak iş görmenin iş sahibinin menfaatine uygun olduğu hallerde vekâletsiz iş görmeye icazet veren iş sahibinin, çoğunlukla yetkisiz temsile de icazet vereceği söylenebilir ${ }^{30}$.

Acaba temsil olunan, iç ilişkide vekâletsiz iş görmeye icazet vermeksizin sadece dıs ilişkide yetkisiz temsile icazet verirse ne olur? Burada ikili bir ayırım yapmak gerekir:

Yetkisiz temsilcinin yaptı̆̆ işlem temsil olunanın menfaatine uygun ise, yani söz konusu işlem câiz olan vekâletsiz iş görme niteliğindeyse, işleme dış ilişkide verilen icazet, şüphe halinde aynı zamanda iç ilişkide vekaletsiz iş görmenin de onaylanması anlamına gelir $^{31}$. Bu halde, temsil olunan ve temsilci arasında BK 415 gereği vekâlet hükümleri geçerli olur. Temsil olunan iç ilişkide vekâletsiz iş görmeye icazet vermediğini ayrıca beyan etmişse, burada sadece

27. Bkz. Zäch: Art. 38 Nr. 65-66.

28. Bkz. Zäch: Art. 38 Nr. 65.

29. Bkz. Violand: sh. 95; Staudinger/Dilcher: $\$ 177$ Nr. 11; Steffen, Erich: (in: Das Bürgerliche Gesetzbuch, Kommentar, herausgegeben von Mitgliedern des Bundesgerichtshofes, Bd. 1, Einleitung, Allgemeiner Teil, Berlin/New York 1974), \& 177 Nr. 7.

30. Tandogan: sh. 275 .

31. Zäch: Art. 38 Nr. 79; Steffen: 8177 Nr. 11. 
BK 413 uygulama alanı bulur ${ }^{32}$. Bu durumda temsilci, söz konusu işlem nedeniyle yapmış olduğu masrafların tazminini temsil olunandan talep edebilir.

Eğer temsilcinin yaptığı işlem temsil olunanın menfaatine uygun değil, dolayısıyla câiz olmayan vekâletsiz iş görme niteliğinde ise, temsil olunan yapılan işleme dış ilişkide icazet vermek ve aynt zamanda da câiz olmayan vekâletsiz iş görmeden doğan taleplerini (BK 411, 414) ileri sürmek hakkını haizdir ${ }^{33}$. Burada, yapılan işlem temsil olunanın menfaatine uygun olmadığından, söz konusu işleme dış ilişkide icazet verilmiş olması, -caiz olan vekâletsiz iş görmeden farklı olarak- icazetin iç ilişki bakımından da verildiği anlamina gelmeyebilir ${ }^{34}$. Bu sebeple, bu konuda temsil olunanın iradesi yorumlanırken, caiz olan vekâlesiz iş görmeye nazaran daha titiz davranmakta fayda vardir. Ancak şüphe halinde, dış ilişkide verilen icazetin iç ilişkiyi de kapsadığını kabul etmek gerekir ${ }^{35}$.

32. Zäch: Art. 38 Nr. 79.

33. Von Bïren: Allgemeiner Tejl, sh. 164; Zäch: Art. 38 Nr. 80; Becker, H.: Berner Kommentar, Bd. VI/, Bern 1941, Art. 38 Nr. 7. Karş. Guhl/Merz/Kummer: sh. 150-151.

34. Bkz. Reichel: sh. 200; Becker: Art. 39 Nr.7; Zäch: Art. 38 Nr. 80.

35. Staudinger/Dilcher: $\& 177 \mathrm{Nr}$. 17; Stefien: $\$ 177 \mathrm{Nr} .4$. 